\title{
Beyond Distance and Time Constrictions: Web 2.0 Approaches in Open Distance Learning, the Case of the University of South Africa (UNISA)
}

\author{
Blessing Mbatha \\ PhD in Information Science, Department of Communication Science \\ University of South Africa \\ E-mail:mbathbt@unisa.ac.za
}

Doi:10.5901/mjss.2013.v4n14p543

\begin{abstract}
Higher education is moving from the traditional model of learning to a completely new socially mediated model. This article reports on the pedagogical value of Web 2.0 tools at Unisa. A quantitative approach was used to conduct this study with a questionnaire as a data collection instrument. The sample size is 301 lecturers drawn by stratified sampling with proportional allocation drawn across all the Unisa colleges. Descriptive statistics were employed to analyse and interpret the data. The results show that Web 2.0 tools are playing a pivotal role when it comes to opening avenues and collapsing the transactional distance in an ODL institution. Combining the developments in web technology and the trend of constructivism can transform the learning process. This article therefore recommends that Unisa should sensitise its lecturers about the adoption of Web 2.0 tools as a new innovative way for enhancing teaching and learning.
\end{abstract}

Keywords: distance education, open distance learning, Web 2.0, new media, electronic learning, distributed learning

\section{Introduction and Background}

Higher education in South Africa is in transition, it is moving from the traditional model of learning to a completely new socially mediated model (Maree, 2011). This transition is also taking place at the University of South Africa (Unisa), and it means that more modern ways of teaching and learning will be adopted. These mostly include new media tools such as podcasts, vodcasts, social networks, blogs, and so forth. However, this change at Unisa has not been welcomed by all academics, which then poses a challenge to its success. It should be noted that for this transition to be successful, academics should play an important role by fully embracing it. Unisa was founded in 1873 as a university college that offered courses to learners through correspondence. The university then migrated through various developmental stages of distance education and it was in January 2004, that it was reconfigured as a comprehensive open distance learning (ODL) university after amalgamation with two similar educational bodies. The 'new' Unisa effectively became the fifth largest ODL education institution in the world, and services approximately 300000 learners (Sonnekus, Louw \& Wilson, 2006). The latter authors further observe that students at Unisa are from both rural and urban areas. This geographical difference impacts on the service delivery of the university, which also has a mandate to enrol a large and diverse student body. Not only is the infrastructure in these areas vastly different, but so is the level of exposure to and availability of modern technology, which influences the level of technical support that can be provided through a learner support system.

Unisa adopted e-learning in order to collapse the transactional distance between the university and its students. Unisa's ODL policy promotes open access to courses, flexibility in learning provision, flexibility in methods and criteria of assessing the learning process and achievements, and lifelong learning as propagated by the Commonwealth of Learning (Sonnekus, Louw \& Wilson, 2006). ODL refers to approaches to learning that focus on freeing learners from constraints of time and place while offering flexible learning opportunities (Mbatha, Naidoo \& Ngwenya, 2010).

Mbatha, Naidoo, and Ngwenya (2010) further note that ODL implies a shift from content to learner, which dictates that the needs of learners be addressed in a holistic manner. The term open distance learning reflects the fact that all or most of the teaching is done by someone removed in time and space from the learner, and that the mission aims to include greater dimensions of openness and flexibility, whether in terms of access, curriculum or other elements of structure (Mbatha, Naidoo \& Ngwenya, 2010). Paily (2013) argues that new developments in the area of information and communication technology (ICT) in general and Web 2.0 in particular have provided a variety of tools and resources for designing and delivering instruction based on the constructivist principles. Paily (2013) describes Web 2.0 as web-based 
utilities and technology tools that focus on social, collaborative, user-driven content and applications. These among other things include blogs, wikis, multimedia sharing services, content syndication, podcasting and content tagging services. Other than interaction, students should also enjoy a richly rewarding and penetrative learning experience (Paily, 2013). Meaningful engagement and dialogue through Web 2.0 can help achieve this in Unisa's ODL context. Furthermore, as initiator of this engagement process, Unisa needs to consider circumstances in its surrounding environment and the specific factors that exist in its environment in order to ensure maximum reach, effectiveness and consequently the success of e-learning (Mbatha, Naidoo \& Ngwenya, 2010).

It is believed that one of the major reasons for some academics not to embrace the transition at Unisa is because they lack knowledge on how Web 2.0 tools can be adopted to improve teaching and learning. Another one is simply the fear of the unknown. Although there are both advantages and disadvantages of using Web 2.0 tools for teaching and learning, the research on which this article is based, focuses on the positive side of these tools as the advantages far outweigh the disadvantages. Another problem in this study stemmed from the fact that not much has been written at Unisa on how Web 2.0 tools can be used to enhance teaching and learning. The current study therefore also intends to close this gap and to augment the body of knowledge. There is fear that if this problem is not properly addressed, the current transition at Unisa may not be successful. It is against this background that through a survey research, the research being reported here sought to identify the pedagogical value of Web 2.0 tools at Unisa in order to improve the university's services to students, and ensure a seamless learning experience which will bridge the transactional distance in its open distance learning context. The research was based on the assumption that Web 2.0 tools facilitate and open avenues for effective teaching and learning because of the potential they have to collapse the transactional distance between students and the institution by allowing easy access to course material, regardless of time and location. This article is significant because of the contribution it can make towards improving throughput at Unisa. After outlining previous relevant literature on Web 2.0 tools, the article reports on the theoretical framework it has adopted as its theoretical framework, reports results, engages in discussion and makes some concluding remarks and provides recommendations based on the results.

\section{Literature Review}

Web 2.0 has become a hot topic in the research of new generation network-related development and application (Fang \& Li, 2013). In support of this view, Paily (2013) notes that new developments in the area of ICTs in general and Web 2.0 in particular have provided variety of tools and resources for designing and delivering instruction based on the constructivist principles. It is hard to avoid the influence that Web 2.0 and social software has within the $21^{\text {st }}$ century (Smith \& Campbell, 2012). Within higher education, there has been a growing awareness that these technological advances are having an impact on teaching and learning.

\subsection{Web 2.0 defined}

Many authors have tried to define the term Web 2.0 and all concur that this term refers to web-based utilities and technology tools that focus on social, collaborative, user-driven content and applications. Paily (2013) is of the view that these applications, among other things, include; blogs, wikis, multimedia sharing services, content syndication, podcasting and content tagging services. Paily (2013) supported by Govanakoppa and Kumara (2013) argues that this emerging technology which is characterised by greater functionality, interoperability and connectivity, helps in knowledge creation through open communication and collaboration. The adoption level of these emerging web technologies is on the rise in academic settings (Paily, 2013). There are also multiple instructional design models based on constructivist pedagogy having the scope to integrate most of the Web 2.0 technologies. Likewise, Smith and Campbell (2012) argue that the above terms are referred to with regularity in all spheres of our lives, and whether we choose to engage with them or not, they are now a major feature of our world. Smith and Campbell therefore describe Web 2.0, as a term that was attributed to Tim O'Reilly in 2005, and can best be defined as the network platform, spanning all connecting devices. In one hand, Web 2.0 applications are seen as those applications that will make the most of intrinsic advantages of that platform whereas social software on the other hand is seen as one of those applications working with them, and from the platform, with extrinsic advantages. 


\subsection{The significance of Web 2.0}

Web 2.0 technologies are becoming more popular in the everyday lives of students. As a result, teachers and designers have begun to explore their use in formal education (Bennett, Bishop, Dalgarno, Waycott \& Kennedy, 2012). In an earlier study, Drexler, Baralt, and Dawson (2008) noted that Web 2.0 represents a collaborative, interactive Internet where individuals can easily share, create, and contribute to global conversations. This next generation web offers unique opportunities for educational application in inquiry practice, collaboration, communication and individual expression, and literacy. Similarly, Vratulis and Dobson (2008) are of the view that the increasing popularity of social software applications through the past 15 years or so has provoked interest in how social hierarchies are developed and modified in internet-based communication environments. There is no escaping the fact that social networking is changing the way people communicate and is transforming the way teaching and learning are conducted. This is more common in distance education institutions. A variety of Web 2.0 applications with educational potential have emerged. Students and lecturers may benefit from exposure to the twenty-first century learning principles obtained through the use of emerging web applications (Drexler, Baralt, and Dawson, 2008). Likewise, Tu, Blocher, and Roberts (2008) note that Web 2.0 technology has evolved modern communication and presentation to a new era. In support of the views above, Tu, Blocher, and Roberts (2008) contend that Web 2.0 technologies empower learners to create personalised and community-based collaborative environments. Tu et al. further note that social networking technology affords learners the opportunity to weave their human networks through active connections to understand what people know and want to know. Moreover, it is believed that social acts that bring out identities, awareness, relationships, connections, and interactions among and between learners are necessary for interactive learning (Tu, Blocher, \& Roberts, 2008). The section below discusses the theory that informed the study.

\subsection{Theoretical framework}

This study adopted the Three Part Model of Interaction posited by Moore (1989) as its theoretical framework. Moore (1999) outlines three types of interaction that are crucial for learning and engagement and they include: learner-content, learner-instructor, and learner-learner.

\subsubsection{Learner-content interaction}

This can best be described as an interaction between the learner and the content or subject of study. Moore and Kearsley (1996) describe the learner-content interaction as a process of individual learners elaborating and reflecting on the subject matter or the course content. In contrast with learner-instructor and learner-learner interactions, Moore and Kearsley (1996) note that only the learner is directly involved in learner-content interaction.

\subsubsection{Learner-instructor interaction}

This is basically the interaction between the learner and the expert who prepared the subject material.

\subsubsection{Learner-learner interaction}

This refers to the interaction between one learner and other learners, alone or in group settings, with or without the realtime presence of an instructor. Moore and Kearsley (1996) describes the learner-learner interaction as a two-way reciprocal communication between or among learners who exchange information, knowledge, thoughts, or ideas regarding course content, with or without the presence of an instructor. However, for teaching and learning to be realised, some kind of interaction has to take place. This could be the student engaging with his/her study material, or a lecturer making use of learning resources to impart skills to the students. Anderson (2003) defines interaction as a key to foster, support and engage learning. Likewise, Moore and Kearsley (1996) note that interaction has been deemed one of the most important components in distance education due to the isolation of instructors and learners. The section below presents the methodology that was adopted to conduct this study. 


\section{Research Methodology}

The survey method was deemed excellent to measure the lecturers' perceptions with respect to the use of Web 2.0 to improve teaching and learning at Unisa. This descriptive study used a survey method because it was a relatively quick and cheap way of obtaining data from the targeted population. It is a very effective and non-experimental quantitative method of obtaining data. It allowed the researcher to carefully choose the population and to organise the data and present it systematically as well as to interpret it relatively easily. Due to the diverse nature of Unisa's community and its large size, this study narrowed its focus down to Unisa's regional hub which is located in Pretoria in the Republic of South Africa. In this region, only lecturers were targeted across all colleges to get their views on the adoption of Web 2.0 to improve teaching and learning at Unisa.

It was vital for this study to establish lecturers' perceptions on Unisa's e-learning system as lecturers will play a major role in the success and the failure of this initiative. Stratified random sampling with proportional allocations was used to select lecturers across all colleges at Unisa (see table 1 below). Then, within the stratas, systematic sampling was used. Stratified random sampling is a probability sampling technique that enables a researcher to select elements randomly by first putting them into non-overlapping homogeneous groups called strata and a random sample is selected from each stratum using either simple random sampling or systematic sampling. Probability samples are utilised such that the researcher is able to generalise the results to the population thus ensuring external validity. In order to conduct an in-depth study and to acquire a demonstrable degree of reliability and validity, the researcher used stratified random sampling to select the population sample. The sample size is 301 lecturers drawn by stratified sampling with proportional allocation drawn across all the Unisa colleges. A total of 301 participants were selected because a smaller sample is more manageable and less costly.

Table 1: Distribution of lecturers per college

\begin{tabular}{|l|c|c|}
\hline \multicolumn{1}{|c|}{ College } & Number of lecturers & Sample size \\
\hline Education & 257 & 28 \\
\hline Agriculture and Environmental Sciences & 945 & 102 \\
\hline Graduate School of Business Leadership & 133 & 14 \\
\hline Science, Engineering and Technology & 274 & 30 \\
\hline Human Sciences & 740 & 80 \\
\hline Graduate Studies & 84 & 10 \\
\hline Law & 345 & 37 \\
\hline TOTAL & 2778 & 301 \\
\hline
\end{tabular}

A self-administered questionnaire consisting of both structured and non-structured questions was used. Since questionnaires are a cheap and cost-effective method, the validity of the data collection instrument that was used in this study was enhanced by the fact that questions were derived from the objectives of this study. Each question was checked to determine whether it contributes to the research objectives. With regard to internal validity, the researcher critically looked at the work to ensure that the research assistants adhere to the topic and measure what the study intends to measure. Internal validity was also ensured by reviewing studies by other researchers in the same field. With regard to reliability, the research instrument was pre-tested in a pilot study for clarity, completeness, relevance and shortcomings. The pilot study aimed to test the subject matter of the current research, the population it is to cover, its spatial variability, and the possible reactions to questions by the respondents. The reliability of the research instruments was enhanced by having both close-ended and open-ended questions. The researcher ensured that simple, direct and unbiased wording was used. Data was analysed by using descriptive statistics and the Statistical Package for the Social Sciences (SPSS). Relationships among variables were compared and interpretations made. Descriptive statistics were employed to further analyse and interpret the data.

In terms of ethical considerations, informed consent was obtained from each participant in the study in order to ensure that he/she understood what he/she was doing and to verify his/her willingness to participate. The respondents were assured of their rights, including the right of consent, protection from disclosure of information, and respect for their privacy. All the research participants participated voluntarily and were not forced to take part in the study. With regard to protection from harm, the researcher ensured that the participants were not at any risk and would not be exposed to embarrassment, unusual stress, or any demeaning treatment. Anonymity and confidentiality were promised and maintained. The information that participants provided was not made available to anyone else who was not directly 
involved in the study and cannot be traced/identified to the participants. The researcher also ensured that the participants would remain anonymous throughout the study. In terms of professional standards, the researcher ensured that the results were gathered in a professional manner without misrepresenting anyone and/or intentionally misleading the respondents about the nature of the study. The researcher ensured that all the results were presented honestly without fabricating any data to support any particular finding. The section below presents the results of the study.

\section{Results}

The results below are reported on the following headings: demographic profile of respondents, characteristics of Web 2.0 tools, benefits of using Web 2.0 in teaching and learning, and essential elements of cooperative learning.

\subsection{Characteristics of respondents}

Background information sought from the respondents included age, gender and highest educational attainment. These structured questions were asked to determine the relationships between demographic characteristics and the use of Web 2.0 tools by lecturers at Unisa. The study was dominated by females (189 in number or $63 \%$ ). This did not at all come as a surprise given the fact that with regard to gender at Unisa, there are more female academics than male academics. This is so despite some earlier studies having identified women and girls as disadvantaged in their uptake of ICTs (Mbatha, Ocholla, \& Le Roux, 2011). The majority (233 or 77\%) of the respondents were between the ages of 29 and 34 , followed by those between the ages of 35 and 40 (45 in total, which means they constituted $15 \%$ of the respondents). Only $23(8 \%)$ of the respondents were over 50 years of age. The aim of this question was two-fold: firstly to ascertain the distribution of respondents by age, and secondly to establish whether there was any correlation between the respondents' ages and their use of Web 2.0 tools. With regard to educational background, at least 178 respondents or $59 \%$ of all the respondents had masters degrees, followed by 89 or $30 \%$ of the respondents who had doctoral degrees. Among all these, only 89 or $11 \%$ of the respondents were professors.

\subsection{Characteristics of Web 2.0 tools}

One of the objectives of the study was to establish whether respondents had knowledge of the characteristics of Web 2.0 tools. The respondents were therefore provided with a list of possible characteristics of Web 2.0 to choose from that were applicable to their situations. Figure 1 below presents the results.

Figure 1: Characteristics of Web 2.0 tools $(n=301)$

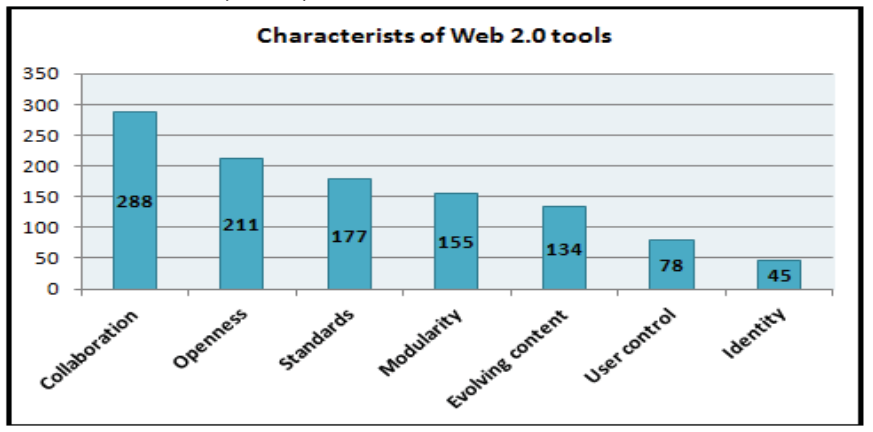

*The graph above represents multiple responses

The figure above depicts that the majority of the respondents, or 288 of them - which is an overwhelming $96 \%$ of them were of the view that collaboration was one of the characteristics of Web 2.0. Also a significant number of respondents, standing at 211 or $70 \%$ stated that openness as one of the characteristics of the Web 2.0, while 177 or $59 \%$ of the respondents indicated that there are certain standard that enable interoperability between applications. Modularity was considered by at least 155 or $51 \%$ of the respondents as one of the characteristics of Web 2.0 , while evolving content was picked up by 134 or $45 \%$ of the respondents. It is noteworthy that 78 or $26 \%$ of the respondents chose user control; while a paltry 45 or $15 \%$ of the respondents felt that identity was one of the characteristics. 


\subsection{Benefits of using Web 2.0 in teaching and learning}

One of the objectives of the study was to establish whether respondents were aware of the pedagogical value of Web 2.0 tools in an ODL context. The respondents were provided with a list of benefits of using Web 2.0 tools for teaching and learning and asked to indicate those that were applicable to their situations. The results are presented on the figure below.

Figure 2: Benefits of the Web 2.0 in teaching and learning $(n=301)$

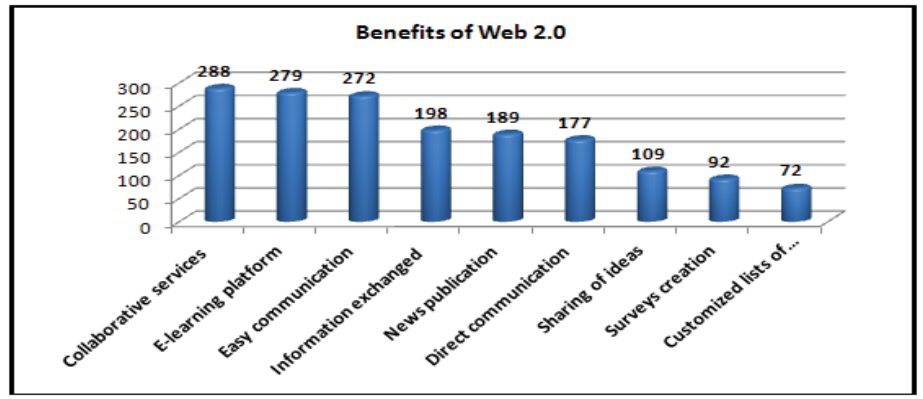

*The graph above represents multiple responses

It can be seen on the figure above, that the majority of respondents (288; $97 \%)$ felt that collaborative services are benefits of using Web 2.0 tools for teaching and learning, while 279 (93\%) chose e-learning platform, and 272 (90\%) opted for easy communication. Those who identified information exchange as one of the advantages were also significant (198; 66\%), while 189 (63\%) chose news publications, and only 177 (59\%) chose direct communication. A mere 109 (36\%) picked sharing of ideas as an advantage, and 92 (31\%) chose surveys creation and only a small number consisting of $72(24 \%)$ felt that customised list of students is one of the advantages of using Web 2.0 tools for teaching and learning.

\subsection{Essential elements of cooperative learning}

Respondents were asked to indicate types of Web 2.0 tools that are essential for enhancing teaching and teaching. Respondents were provided with a list of Web 2.0 tools to choose from that were applicable to their situations. The results are presented in the figure below.

Figure 3: Essential elements of cooperative learning ( $\mathrm{N}=301)$

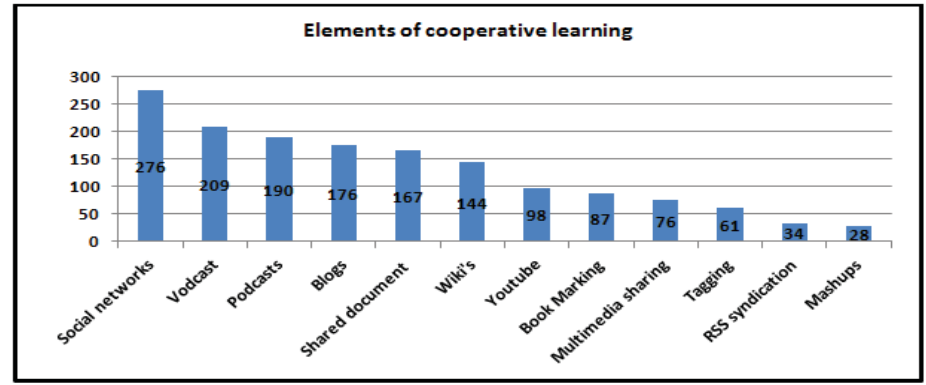

*The graph above represents multiple responses

The results on the figure above show that the majority of respondents -276 or $92 \%$ of them felt that social networks are essential in improving teaching and learning. Furthermore, the results show that 209 (69\%) chose vodcasts, 176 (58\%) went for blogs, 167 (55\%) believed shared documents would do, while Wiki's scored 144 (48\%). YouTube got 98 (33\%) 
while book marking scored 87 (29\%), multimedia stood at 76 (25\%), tagging retained only 61 or 20\%, and RSS syndication scored $34(11 \%)$, and only $28(9 \%)$ of respondents indicated mashups as one of the elements of cooperative learning.

\section{Discussion}

One of the problems investigated in this study was some lecturers' reluctance to embrace the transition that is currently taking place at Unisa. This was believed to be attributed to the lack of lecturers' knowledge on the advantages of using Web 2.0 tools to enhance teaching and learning in an ODL context, hence Unisa was used as a case study. However, the results of this study paint an unexpected picture with regard to the knowledge of lecturers in as far as the use of Web 2.0 to enhance teaching and learning is concerned. For example, when respondents were asked to indicate the characteristics of Web 2.0 tools, a whopping number of respondents which is 288 or $96 \%$ of them were of the view that Web 2.0 is driven by participation and collaboration because social tools like blogs and wikis encourage people to create, collaborate, edit, categorize, exchange, and promote information. In support of the results above, Smith and Campbell (2012) are of the view that Web 2.0 tools are capable of allowing users to interact and collaborate with each other in a social media dialogue as creators of user-generated content in a virtual community, in contrast to websites where people are limited to the passive viewing of content.

Interpreted in light of the Three Part Model of Interaction posited by Moore (1989), the results and the information above can be regarded as learner-content interaction. The learner-content interaction is a process of individual learners elaborating and reflecting on the subject matter or the course content. This can be done by using Web 2.0 tools to access vast amounts of information from the internet. Also, the majority of respondents, 211 of them or simply $70 \%$, were of the opinion that the world of Web 2.0 has only become possible through a spirit of openness whereby developers and companies provide open, transparent access to their applications and content. Likewise, a huge number of the respondents (117 or 59\%) knew that there are certain standards by which various Web 2.0 tools are developed so that there is a fixed data structures and communication protocols which enables interoperability between applications. The results also show that respondents were aware that Web 2.0 emerges from many, many smaller technologies that are designed to link and integrate with others.

When asked to indicate the benefits of using Web 2.0 tools for teaching and learning, most respondents seemed to have a clear understanding of the Web 2.0 benefits for teaching and learning. It is interesting to note that despite the fact that some lecturers at Unisa are reluctant to embrace the idea of teaching online at Unisa, the results of this study show that they a number of them is well aware of the benefits of using Web 2.0 tools for teaching and learning. The assumption of this study was that one of the reasons lecturers are not fully embracing the transition that is currently taking place at Unisa, is because they are unaware of the benefits of using Web 2.0 tools to enhance teaching and learning. Respondents were also aware that the Web 2.0 tools are capable of speeding up communication, information exchange, and sharing of ideas. It should be pointed out that this is what ODL is all about. This is how transactional distance is bridged. As Stanciu, Mihai, and Aleca (2012) note, there are many possible uses of Web 2.0 tools in education which will provide value to the educational process.

In support of the aforementioned views, Bogdan, Patrut, and Cmeciu (2013) assert that Web 2.0 tools play a vital role in our society including education. The latter authors further contend that Web 2.0 tools have emerged as an important tool in the creation and exchange of user-generated content and social interaction. They observe that the benefits of these services have entered in the educational areas to become new means by which scholars communicate, collaborate and teach. Similarly, John (2013) in line with the latter authors is of the view that Web 2.0 tools offer new media for learning and teaching both inside and outside the classroom.

It is important to note that these tools can be used for reflection as part of a course, or as an ongoing tool for reflecting on experience and sharing ideas. Students and teachers/lecturers enjoy blogging and use it for community building, resource consolidation, sharing ideas or as a personal journal. It should also be pointed out that the ability to comment on one's blogs means that this learning can be further enhanced by allowing others to comment on the content of posts, ask questions, and suggest resources (Paily, 2013). Chi-Kim (2011) is of the view that the nature of knowledge is being redefined by a new media landscape that allows all participants to be media producers and owners. He further argues that without a comprehensive strategy to include Web 2.0 tools and social media practices within schools, powerful new skills will be neither harnessed, nor developed. Chi-Kim (2011) further contends by saying that despite the challenge to the relationship between students (digital natives) and teachers (digital immigrants) that Web 2.0 tools present, teachers are still the vital link to supporting students and giving meaning to the practices they engage in, 
including developing critical thinking in an information age. Similar sentiments are shared by Smith and Campbell (2012) who observe that the trend for the informal consumption, creation, communication and sharing of knowledge through use of Information and communication technologies (ICT) have set an increased demand with the emergence of Web 2.0 applications.

In support of the views above, Wellburn and Eib (2010) note that the uptake of Web 2.0 and social software tools is gaining momentum in all sectors of the education industry. In particular, Web 2.0 is seen to hold tremendous potential for addressing the needs of distance students, enhancing their learning experiences through increased connectivity, customisation, personalisation, and rich opportunities for networking and collaboration. Likewise, Bower, Hedberg, and Kuswara (2010) are strengthening the views above by mentioning that there has been an explosion in the number of Web 2.0 tools available for educators to use with their students. Similarly, Postigo $(2011,182)$ supported by Ofulue (2011) argues that the use of ICTs to bridge the communication gap between teacher and learner has been identified as one of the most significant features of ODL delivery systems. Lemke, Coughlin, Garcia, Reifsneider and Baas (2009) supported by Pan and Franklin (2011) note that the use of Web 2.0 tools offers learners the opportunity to interact with information of high quality and depth. Kan (2011) observes that Web 2.0 tools facilitate collaboration and interaction, offer possibilities for immediate feedback, foment social connections and communities, and harness collective intelligence with no associated costs. In strengthening these views, Martin and Noakes (2012) argue that as technology continues to flatten the world and as Web 2.0 changes the way knowledge is created and shared, tertiary education institutions are turning increasingly to e-learning to extend access to students globally as well as to improve the quality of their learning experience.

\section{Conclusion}

The problem that was investigated in this study pertained to some academics' reluctance to embrace the transition that is currently taking place at Unisa. In essence, the transition referred to here is the transformation in teaching and learning. The new method of teaching and learning includes the use of Web 2.0 tools to improve the students' learning experience. Another problem in this study stemmed from the fact that not much has hitherto been written at Unisa on pedagogical value of Web 2.0 tools. Hence this article intended to close this digital gap in the literature and add to the body of knowledge in this new field. This article sought to identify the pedagogical value of Web 2.0 tools at Unisa in order to improve the university's services to students; ensure a seamless learning experience, and bridge the transactional distance in its open distance learning context.

As already indicated, this article was based on the assumption that Web 2.0 tools facilitate and open avenues for effective teaching and learning because of the potential that they have in terms of dealing decisively with the transactional distance between students and the institution by allowing easy access to course material, regardless of time and location. The results clearly show that Web 2.0 tools are indeed playing a pivotal role when it comes to opening avenues and capability to collapse the transactional distance in an ODL institution. It could also be argued that the reason for some lecturers not completely embracing the new transition, is not due to the lack of knowledge about the benefits of using Web 2.0 tools to improve teaching and learning, but could simply be fear of the unknown. Research shows that some lecturers are simply resistant to change and thus, they fear a new way of doing things. This is so because the results categorically show that most respondents knew that one of the benefits of using Web 2.0 tools is to improve teaching and learning. In addition, respondents were even able to identify types of Web 2.0 tools that can be used to enhance teaching and learning in an ODL institution such as Unisa. The Diffusion of Innovations Theory (Dol) is one of the theories that explain the acceptance of technology. The Dol is essentially a social process in which subjectively perceived information about a new idea is communicated and rests on the premise that a new idea, practice or object has perceivable channels, time and mode of being adopted by individual or organisations. In connection to this article, a new idea or innovation is Web 2.0. The Dol purports that those innovations which are perceived by individuals as having greater relative advantage, compatibility, trialability and observability will be adopted more rapidly than those which are perceived as more complex. In this case one may assume that the reasons why some of the Unisa lecturers do not adopt the use Web 2.0 in their teaching, it is because they find these tools not user-friendly and not having any relative advantage in enhancing the way they teach.

Based on the results reported on in this article, it is safe to say that Web 2.0 tools can provide new opportunities for designing and delivering instruction based on the constructivist principles. Combining the developments in Web technology and the trend of constructivism can transform the learning process. Web 2.0 tools provide access to rich sources of authentic information; encourages meaningful interactions with content; and brings people together to 
challenge, support, or respond to each other with the help of multiple collaborative tools. It is also important to note that Web 2.0 technology aims to enhance mediated knowledge creation, information sharing, personalised structures, and, most notably, collaboration among users. Emerging Web 2.0 tools are capable of offering richer and greater possibilities for people to connect, share ideas, and participate in global communities than were previously available. Another point worth mentioning is that in combination with appropriate learning designs and pedagogical strategies, these technologies hold enormous promise for enhancing, enriching, and extending traditional paradigms of distance education.

This article therefore recommends that Unisa should sensitise its lecturers about the adoption of Web 2.0 tools as a new innovative way for enhancing teaching and learning. The use of Web 2.0 to bridge the communication gap between teacher and learner has been identified as one of the most significant features of ODL delivery systems. It is worth mentioning that the vital implications of Web 2.0 for ODL are the new possibilities for extending and enriching the learning experience, reducing isolation, and utilising the power and immediacy of the available tools to support the core learning processes of reflection, collaboration, knowledge creation, creativity, discussion, and social networking. With that said, it should be safe to say Web 2.0 tools are revolutionising the way teaching and learning are conducted and if the status quo remains, they will continue to do so for a long period.

\section{References}

Anderson, T. (2010). Theories for Learning with Emerging Technologies. In: Veletsianos, G. Immerging technologies in Education. AU Press: Edmonton, 23-36.

Bennett, S., Bishop, A., Dalgarno, B., Waycott, J. \& Kennedy, G. (2012). Implementing Web 2.0 Technologies in Higher Education: A Collective Case Study. Computers \& Education, 59(2), 524-534.

Bogdan, P., Patrut, M. \& Cmeciu, C. (2013). Social Media and the New Academic Environment: Pedagogical Challenges.IGI Global: Hershey, PA.

Bower, M., Hedberg, J.G. \& Kuswara, A. (2010). A framework for Web 2.0 learning design. Educational Media International, 47(3), 177198.

Chi-Kim, C. (2011). Web 2.0: Challenges and Opportunities for Media Education and Beyond. E-Learning and Digital Media, 7(4), 328337.

Drexler, W., Baralt, A. \& Dawson, K. (2008). The Teach Web 2.0 Consortium: a tool to promote educational social networking and Web 2.0 use among educators. Educational Media International, 45(4), 271-228.

Fang, H. \& Li, X. (2013). Web 2.0 Application in Subject Services of High School Libraries. Information Technology Journal, 2(3), 458461.

John, O. (2013). Dynamic and Interactive Mathematics Learning Environments: Opportunities and Challenges for Future Research, Mevlana International Journal of Education, 3(3), 8-24.

Kan, S. O. R. (2011). Cooperative learning environment with the Web 2.0 tool e-portfolios. Turkish Online Journal of Distance Education, 12(3), 201-214.

Lemke, C., Coughlin, E., Garcia, L., Reifsneider, D. \& Baas, J. (2009). Leadership for Web 2.0 in education: promise and reality. Culver City, CA: Metiri Group. Commissioned by CoSN through support from the John D. and Catherine T. MacArthur Foundation.

Maree, C. (2011). Exploring the implications, challenges and potential of new media and learning. On the Horizon, 19(4), 245-252.

Martin, M. \& Noakes, M. (2012). Fostering a web 2.0 ethos in a traditional e-learning environment. Electronic Journal of e-Learning, 10(3), 284-292.

Mbatha, B. T. (2013). Facebook: the power source of transforming the learning experience. International Journal for e-Learning Security 3(1), 23--39.

Mbatha, B. T., Naidoo, L. \& Ngwenya, B. (2010). Bridging the transactional gap in Open Distance Learning (ODL): The case of the University of South Africa. Inkanyiso, Journal Humanities and Social Sciences, 2(1), 64-69.

Mbatha, B. T., Ocholla, D.N. \& Le Roux, J. (2011). Some implications of Information and Communication Technologies on public service work environments in South Africa. Information Development. 27(4), 47-62.

Mbatha, B. T. \& Manana, K.P.P. (2012). Students' perceptions on the use of Facebook in an ODL landscape, Progressio, 34(1), 13-26.

Mbatha, B. T. \& Naidoo, L. (2010). Problems hampering the collapse of distance in ODL, Progressio. 32(1), 170-184.

Moore, M. G. (1989). Three types of interaction. The American Journal of Distance Education, 3(2): 1-6.

Moore, M. G., \& Kearsley, G. (1996). Distance education: A systems view. Boston, MA: Wadsworth Publishing.

Ofulue, C. I. (2011). Survey of barriers affecting the use of Information Communication Technologies among distance learners: a case study of Nigeria. Turkish Online Journal of Distance Education, 12(3): 145-154.

Paily, M. U. (2013). Creating Constructivist Learning Environment: Role of "Web 2.0" Technology International Forum of Teaching and Studies, 9(1), 39-50.

Pan, S. C. \& Franklin, T. (2011). In-Service Teachers' Self-Efficacy, Professional Development, and Web 2.0 Tools for Integration. New Horizons in Education, 59(3), 28-40.

Postigo, H. (2011). Questioning the Web 2.0 Discourse: Social Roles, Production, Values, and the Case of the Human Rights Portal. The Information Society, 27(1), 181-193. 
Rogers, E. M. (1995). Diffusion of Innovations, New York: Free Press.

Sonnekus T. P., Louw, W. \& Wilson, H. (2006). Emergent Learner Support at University of South Africa: An Informal Report. Progression. 28(1 \& 2), 44-53.

Stanciu, A., Mihai, F. \& Aleca, O. (2012). Social networking as an alternative environment for education. Accounting and Management Information Systems 11(1), 56-75.

Tu, C., Blocher, M \& Roberts, G. (2008). Constructs for Web 2.0 learning environments: a theatrical metaphor. Educational Media International, 45(4), 253-269.

Vratulis, V. \& Dobson, T.M. (2008). Social negotiations in a wiki environment: a case study with pre-service teachers. Educational Media International, 45(4), 285-294.

Wellburn, E. \& Eib, B.J. (2010). Imagining Multi-Roles in Web 2.0 Distance Education. In: Veletsianos, G. Immerging technologies in Education. AU Press: Edmonton. pp. 62-87. 